\title{
Application of Analytic Hierarchy Process in the Selection
}

\section{of Educational Supervisors}

\author{
Shu-Mei Huang ${ }^{1}$, Chia-Ju Liu ${ }^{2}$
}

${ }^{1}$ Doctoral student, Department of Science Education and Environmental Education, National Kaohsiung Normal University, Kaohsiung, Taiwan

${ }^{2}$ Professor, Department of Science Education and Environmental Education, National Kaohsiung Normal University, Kaohsiung, Taiwan

Received: 13 Nov 2020; Received in revised form: 22 Dec 2020; Accepted: 14 Jan 2021; Available online: 20 Jan 2021

(C2021 The Author(s). Published by The Shillonga Publication. This is an open access article under the CC BY license

(https://creativecommons.org/licenses/by/4.0/).

\begin{abstract}
In this study, through literature review and analytic hierarchy process, expert questionnaires were conducted to explore the dimensions and criteria for selecting educational supervisors, four evaluation dimensions and 22 evaluation criteria were constructed, and the weight and ranking of each criterion item were determined by using hierarchical analysis. Through systematic and scientific professional knowledge, we can find out the key factors that affect the selection of educational supervisors: professional ability is the most important, followed by leadership and personality traits. Experience, team spirit and professional knowledge are the three most important criteria.
\end{abstract}

Keyword-analytic hierarchy process, educational supervisors.

\section{RESEARCH BACKGROUND}

Based on the success or failure of enterprise operation, the leader is one of the key points (Robbins, 1989). Therefore, organizations must be driven by managers with sufficient expertise, skills and capabilities. Management ability is the combination of experience, responsibility, knowledge and skill. On the one hand, it refers to the ability of the supervisor to perform the task, on the other hand, to judge whether the manager is competent for its work.

Many organizations have many problems in the process of talent selection, mainly as follows: in the selection criteria, they ignore the necessary quality characteristics of talents themselves; in the selection scope, there are too many rules and regulations, single channels, and narrow range of knowledge; in the selection of talents, there are many problems; In the way of personnel selection, it is still based on organizational appointment or appointment, ignoring the role of market competition, which does not meet the educational needs of modern market economy, and lacks the scientificity and universality of personnel selection and appointment.

Talent selection is a process in which an organization, in order to meet the needs of its development and according to the requirements of human resource planning and job analysis, seeks to attract those who are both competent and 
interested in working in the unit, and selects suitable personnel to be employed, so as to ensure that the activities of the organization are carried out normally. Therefore, talent selection is a very important basis for school activities.

\section{LITERATURE REVIEW}

Fatma \& Ali (2008) Supervision in education plays a crucial role in attaining educational goals. In addition to determining the present situation, it has a theoretical and practical function regarding the actions to be taken in general and the achievement of teacher development in particular to meet the educational goals in the most effective way. For the education supervisors to act ethically in their tasks while achieving this vital mission shall facilitate them to build up trust, to enhance the level of collaboration and sharing, thus it shall contribute to organizational effectiveness. Ethics is an essential component of educational supervision. It demonstrates rather vague quality due to the conditions, persons, and situations. Therefore, it is a difficult process to develop the ethical standards in institutions. This study aims to clarify the concept of ethics, to bring up its importance, and to make recommendations for more effective supervisions from the aspect of ethics, based on the literature review, some research results, and sample cases reported by teachers and supervisors.

Joo \& Hyun-Jun (2013) this study investigates on how to improve the selection system of educational supervisors. The content anaylsis was conducted on the 2013 plan for selecting educational supervisor in the offices of Education in 17 different cities and provinces, focusing on candidates, selection process and criteria. In addition, the study reviewed the validity and effects of improvement plans suggested in previous studies, and later it concluded with additional improvements. Details are as follows. Requirements for candidates were recommendation, educational experience, performance evaluation, and the history of previous application. Selection process included multistep process, various selection methods, and tests for basic knowledge and professional capability. Outside experts were invited to become members of the selection committee. This study concluded with additional improvement plans, such as the alternative plan for promotion, enhanced requirements for professional capability, improved leadership of superintendent.

Atila \& Batu (2010) the aim of this study is to find out whether private and public primary schools directors show ethical behavior. In the research survey method was used. The data was collected with "Ethical Leadership Scale". Ttest was used for the analysis of data, the significance of data was found to be .05 . The result of the study indicate that school and private primary school director display high ethical leadership behavior, mostly in communication dimension which is a sub-dimension of ethical leadership behaviors. Besides, it was found out that private school directors show more ethical leadership behavior than in all four sub-dimension of ethical behavior compared to public school directors.

\section{METHODOLOGY}

The analytic hierarchy process (AHP) takes a hierarchical approach to all elements related to decision making and adopts as many concepts as possible to form opposites. It can establish a hierarchical system for complex plans and make comparisons between elements of different scales. For decision makers, hierarchy is conducive to the understanding of things. When faced with the choice of an appropriate plan, evaluation of alternative plans must be conducted according to certain criteria to determine the priority of each alternative plan, which is mainly applied to decision-making problems with multiple evaluation criteria in uncertain situations. 


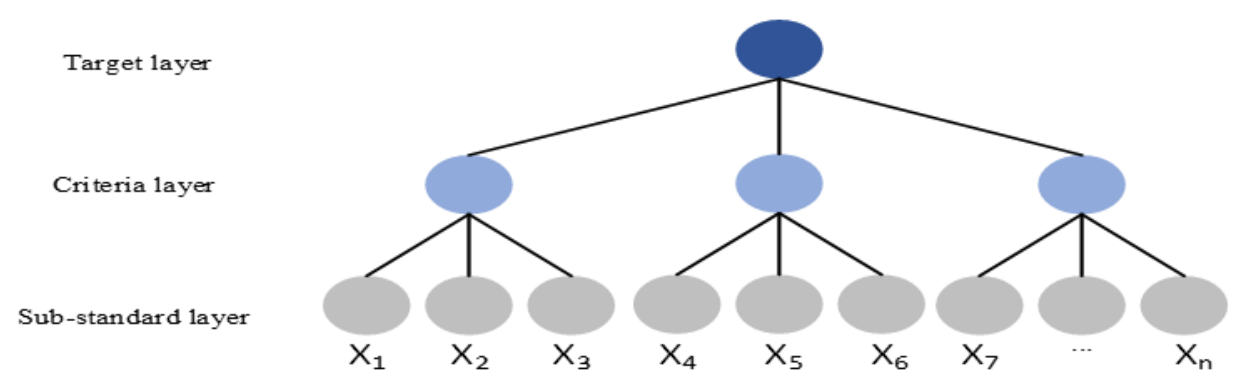

Fig.1: Hierarchical structure diagram of analytic hierarchy process

According to Teng and Tseng (1989a, 1989b), the main basic assumptions of AHP include the following nine items: (1) In an analytical system, it can be decomposed into several layers and elements to form a directed network.

(2) In a hierarchy, the elements of each hierarchy are assumed to be independent.

(3) Each element within the hierarchy can be evaluated under the criteria of the previous hierarchy.

(4) When comparing and evaluating the elements, hierarchical analysis can convert nominal scale into ratio scale.

(5) In Pair wise comparison between elements, Positive reciprocal matrix can be used for further treatment.

(6) When the elements are compared in pairs, the preference relationship of the evaluator meets Transitivity. This means that not only the priority relationship satisfies the transitivity ( $\mathrm{A}$ is better than $\mathrm{B}, \mathrm{B}$ is better than $\mathrm{C}$, so $\mathrm{A}$ is better than $\mathrm{C}$ ), but the strength relationship also satisfies the transitivity ( $\mathrm{A}$ is twice better than $\mathrm{B}, \mathrm{B}$ is three times better than $\mathrm{C}$, so $\mathrm{A}$ is six times better than $\mathrm{C}$ ).

(7) In practice, however, it is not easy to be completely recursive, so non-recursive consistency must be verified.

(8) The degree of priority of elements is determined by the weighting principle.9. The presence of any element in the framework, regardless of its degree of strength, is considered relevant to the overall assessment framework.

\section{RESULTS}

(1) Constructs level project weight analysis: in Constructs, the weight of Expertise is the highest (0.744), followed by Leadership (0.168), personality traits (0.087). According to the expert decision, the evaluation of professional ability in the three major Constructs is the primary element under the general objective of the evaluation of the Laboratory Supervisor, which is more important than the other evaluation projects. The C.I. value is 0.033 and the C.R. value is 0.056 . As C.I. is less than 0.1 and C.R. $<0.1$ indicates that the level of the level of the level of the level of the layer is acceptable, as shown in table 1 .

Table 1 Constructs selection and weight ranking for educational supervisors

\begin{tabular}{|l|c|c|}
\hline \multicolumn{1}{|c|}{$\begin{array}{c}\text { Decision model of educational } \\
\text { supervisor's selection constructs }\end{array}$} & Weight & Ranking \\
\hline Expertise & 0.744297 & 1 \\
\hline Leadership & 0.168578 & 2 \\
\hline personality traits & 0.087125 & 3 \\
\hline
\end{tabular}

(2) Criterion level project weight analysis:

(a) Of the two criteria under Expertise constructs, the highest (0.857) of the experienced variable weights shows that the experience variable is the most important condition in evaluating the project when evaluating the professional ability. The second is professional knowledge (0.142). The C.I. value is 0 and the C.R. value is 0 . The consistency of the three criteria 
under the C.I. $<0.1$ and C.R. $<0.1$ is an acceptable level, as shown in table 2 .

Table 2 Criteria weight and ranking under Expertise constructs

\begin{tabular}{|c|c|c|}
\hline $\begin{array}{c}\text { Expertise constructs - } \\
\text { Criteria weight and } \\
\text { ranking }\end{array}$ & Weight & Ranking \\
\hline Experience & 0.85798 & 1 \\
\hline Professional knowledge & 0.14202 & 2 \\
\hline
\end{tabular}

(b) Under the leadership of constructs, the three criteria were group spirit $(0.753)$, the highest weight, followed by communication coordination $(0.154)$, supervision guidance (0.09). It shows that when evaluating experts' leadership ability, the group spirit is the most important condition for evaluating the project. The C.I. value is 0.015 and the C.R. value is 0.027 . The consistency of the three criteria under the C.I. $<0.1$ and C.R. $<0.1$ is very high, as shown in table 3 .

Table 3 Criteria weight and ranking under leadership constructs

\begin{tabular}{|l|c|c|}
\hline \multicolumn{1}{|c|}{$\begin{array}{c}\text { Leadership constructs - } \\
\text { Criteria weight and ranking }\end{array}$} & Weight & Ranking \\
\hline Group spirit & 0.753141 & 1 \\
\hline Communication Coordination & 0.154886 & 2 \\
\hline Supervision guidance & 0.091973 & 3 \\
\hline
\end{tabular}

(c) Under the personality trait constructs, the three criteria were highest ethical practice (0.754), followed by emotional management (0.156), and self-confidence (0.088). It shows that when evaluating experts' personality traits, experts believe that moral integrity is the most important condition in evaluating items. The C.I. value is 0.017 and the value of C.R. is 0.029 . The consistency of the three criteria under the C.I. $<0.1$ and C.R. $<0.1$ is an acceptable level, as shown in table 4.

Table 4 Criteria weight and ranking under personality trait constructs

\begin{tabular}{|l|c|c|}
\hline $\begin{array}{c}\text { Personality trait constructs } \\
\text { - Criteria weight and } \\
\text { ranking }\end{array}$ & Weight & Ranking \\
\hline Ethical practice & 0.754838 & 1 \\
\hline Emotion management & 0.156672 & 2 \\
\hline Self-confidence & 0.08849 & 3 \\
\hline
\end{tabular}

(3) Confirm the selection of the constructs and the weight of the criteria for the educational supervisors

The whole level weight ratio of the educational supervisor's selection framework is shown in table 5 .

Table 5 The weight ratio of the level of the selection of the educational supervisors

\begin{tabular}{|c|c|c|c|c|c|}
\hline Constructs & Constructs Weight & Criterion & Criterion Weight & Total Weight & Total Ranking \\
\hline \multirow{2}{*}{ Expertise } & \multirow{2}{*}{0.744297} & Experience & 0.85798 & 0.638592 & 1 \\
\hline & & Professional knowledge & 0.14202 & 0.105705 & 3 \\
\hline \multirow{3}{*}{ Leadership } & \multirow{3}{*}{0.168578} & Group spirit & 0.753141 & 0.126963 & 2 \\
\hline & & Communication Coordination & 0.154886 & 0.02611 & 5 \\
\hline & & Supervision guidance & 0.091973 & 0.015505 & 6 \\
\hline \multirow{3}{*}{$\begin{array}{c}\text { Personality } \\
\text { trait }\end{array}$} & \multirow{3}{*}{0.087125} & Ethical practice & 0.754838 & 0.065765 & 4 \\
\hline & & Emotion management & 0.156672 & 0.01365 & 7 \\
\hline & & Self-confidence & 0.08849 & 0.00771 & 8 \\
\hline
\end{tabular}


The data show that the relative weights of expertise, leadership and personality traits are $74.4 \%, 16.8 \%$ and $8.7 \%$ in the three evaluation aspects of the educational supervisors, of which the weight value obtained by expertise is the highest and the value of the other two items is larger than the other two items, showing that experts agree that professional ability projects are available. Conditions are most important for selecting educational supervisors, and personality traits are considered by experts as relatively low importance items. Under the weight of the whole hierarchy, the first three items with higher criteria weight are $63.8 \%, 12.6 \%$ and $10.5 \%$ respectively. The first three conditions considered in the evaluation of the educational supervisors and the weight of confidence in the personality trait are considered as the first three conditions considered by the experts. The $0.7 \%$ is what experts consider relatively low importance.

\section{DISCUSSION AND SUGGESTION}

This study is based on the results of index weight numerical analysis:

(1) The three evaluation of constructs were "Leadership", "Personality trait", "Expertise", the weight value from large to small order: Expertise, Leadership, Personality traits. The weight value obtained by Expertise is $74.4 \%$, which is far greater than other conditions. The expert group believes that professional competence is the most important for the selection of educational supervisors; and personality traits are considered by the expert group to be relatively low in importance.

(2) The weight values of the eight evaluation criteria are from large to small: Experience, Group spirit, Professional knowledge, Moral integrity, Communication coordination, Supervision guidance, Emotional management, Self-confidence.

(a) Experience is the most important evaluation criterion in Expertise (standard weight $85.79 \%$, level weight $63.85 \%$ ); experience refers to the knowledge and technology of completing the task in the ability to be engaged in a specialized profession, and is regarded as the ability to give full play to various abilities. The selection of educational supervisors is a professional and technical entity, and professional competence is the most important part of the enterprise whenever and wherever. Experience is also the most important assessment option unanimously identified by all expert groups in the guideline level.

(b) The group spirit is the most important evaluation criterion in the leadership of the main structure $(75.31 \%$ of the criterion weight, the weight of the whole level $12.69 \%$ ); In leadership, the group spirit is a very important evaluation option for the expert group.

(c) Professional knowledge is a secondary evaluation criterion $(14.2 \%$ of criteria weight, $10.57 \%$ of the whole level). In the management of individual professional knowledge, the process of pursuing the goal, and the ability to display technical support, guidance and problem solving, will affect the quality and safety of the whole work. In ability, it is agreed that professional knowledge is a very important assessment option for educational supervisors. 


\section{REFERENCES}

[1] Atila Y, \& Batu, B. (2010). Teachers' views about ethical leadership behaviors of primary school directors. Procedia Social and Behavioral Sciences, 2(2), 4109-4114.

[2] Joo, \& Hyun-Jun. (2013). A study on the selection of educational supervisors. The Journal of Local Education Management, 17(2), 53-70.

[3] ÖZMEN Fatma, \& GÜNGÖR Ali. (2008). Ethics in education supervision. Inonu University Journal of the Faculty of Education, 9(15), 10-21.

[4] Robbins (1989). Essentials of Organizational Behavior, London : Prentice-Hall Inc.

[5] Teng, J.Y. and Tseng, K. H. (1989a). Connotation Characteristics and Application of AHP (I), China Statistics Journal, 27(6), 13707-13724.

[6] Teng, J.Y. and Tseng, K. H. (1989b). Connotation Characteristics and Application of AHP (II), China Statistics Journal, 27(7), 13767-13786. 